\title{
Kicked in the Face by a Fish
}

\author{
Talal Rane ${ }^{1}$, Samir Taha ${ }^{2 *}$ \\ ${ }^{1}$ Department of Oral \& Maxillofacial Surgery, Al-Ahli Specialist Hospital, Doha, Qatar \\ ${ }^{2}$ Department of Oral \& Maxillofacial Surgery, Al-Wakra Hospital, Hamad Medical Corporation, Doha, Qatar \\ Email: :STAHA3@hamad.qa
}

Received 18 October 2015; accepted 15 December 2015; published 18 December 2015

Copyright (C) 2015 by authors and Scientific Research Publishing Inc.

This work is licensed under the Creative Commons Attribution International License (CC BY). http://creativecommons.org/licenses/by/4.0/

(c) () Op Open Access

\begin{abstract}
Facial trauma caused by animals is a well known aetiology for maxillofacial injuries. Our case is an injury to the midface and upper face, caused by an unusual animal in the world of maxillofacial trauma, in circumstances not very commonly seen, and certainly only exists in few parts of the world. This assault results in a fracture in one of the stronger corners of the orbital cavity rather than the commonly seen floor fractures which is partly likely to break first with blunt external trauma.
\end{abstract}

\section{Keywords}

\section{Maxillofacial Injury, Fish, Midface}

\section{Introduction}

Animal assault to human is a documented cause for facial fractures; literature is full of documentation of different soft and hard tissue trauma caused by anything from animal bites [1], to kicks, most commonly by horses [2].

Animal bites are a significant public health problem, with the majority of bites coming from dogs, cats and humans. These may present as punctures, abrasions, tears, or avulsions. The clinical presentation and appropriate treatment of infected bite wounds vary according to the animal and causative organisms. The management of animal bites is an evidence poor area and most recommendations are based on small case series, microbiological data and expert opinion.

We present a case of facial orbital trauma that results in an orbital fracture not readily explicable by the causative factor. This is caused by a small to medium size fish hitting the face with its tail, outside water.

\section{Case Report}

A 33-year-old male was admitted under neurosurgery and maxillofacial surgery on 25/4/2008 having been hit by "Corresponding author. 
fish tail on the face according to the A \& E services.

The description of the events that lead to the injury was that he was fishing at night sat in his boat, he heard movement in the water right behind him, he then decided to shine a bright light torch to the water to see what was happening, suddenly a fish flew up in the air and hit his right eye, and escaped unharmed back to the sea, the fish was described by the patient as a $30 \mathrm{~cm}$ long of the type called locally as Hakool, this was confirmed from the website of the Qatar Marine to be the Needlefish [3] [4].

Patient was conscious, orientated with BP 142/95, and 15/15 on the Glasgow scale. Saturation of $99 \%$, airway was stable and spine is clear of injury.

Maxillofacial examination showed a severe periorbital bruise, mild proptosis, subconjunctival haemorrhage with no posterior border, bruising over the frontal area, reactive pupils of normal size.

CT scan examination revealed orbital roof/medial wall fracture on the right side and globe displacement due to orbital oedema, pneumocephalus and orbital emphesyma can also be seen on the ct due to involvement of the Ethmoidal air cells in the medial wall.

Needlefish are slender fish, ranging from 3 centimetres to $1 \mathrm{~m}$ in length. Their most distinctive feature is their long narrow beak, which bears multiple sharp teeth. Their upper jaw is smaller than the lower, they feed on fish once the beak fully develops (Figure 1 and Figure 2) [5].

Needlefish are capable of jumping out of the water at up to $60 \mathrm{~km} / \mathrm{h}$. they swim near the surface, and often leap over the decks of shallow boats rather than going around. This jumping activity is apparently excited by light at night; night fisherman and divers in areas across the areas where they are known to exist have been occasionally "attacked" by needlefish diving towards the light source at high speed.

The 33 year old male fisherman was brought in with fracture of the orbital roof/medial orbital wall junction, and pneumocephalus (Figure 3), he had right peri-orbital ecchymosis, making it difficult to examine the eye, therefore opthalmic opinion was sought, he had no globe injury.

The patient was admitted for neuro and eye observation, ct scan was taken which revealed a lot of oedemamedial to the eyeglobe, a fracture of the orbital roof/medial wall area with orbital emphysema and mild pneumocephalus, the fracture was posterior and lateral to the naso-frontal duct (Figure 4 and Figure 5) which was not

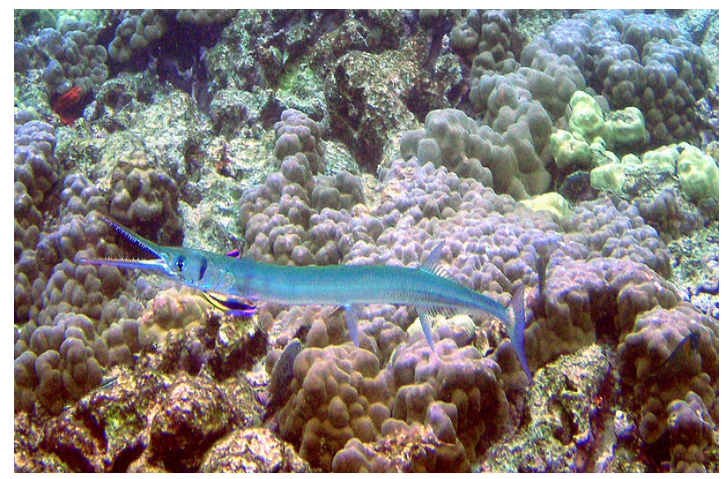

Figure 1. Ocean type needlefish.

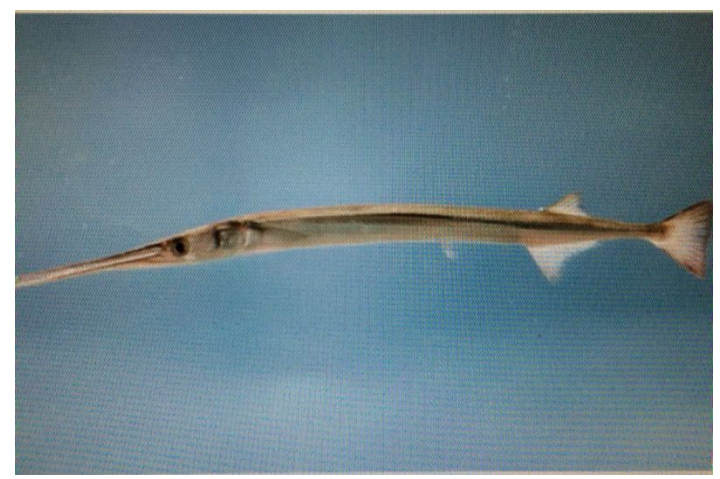

Figure 2. Close-up view needlefish. 


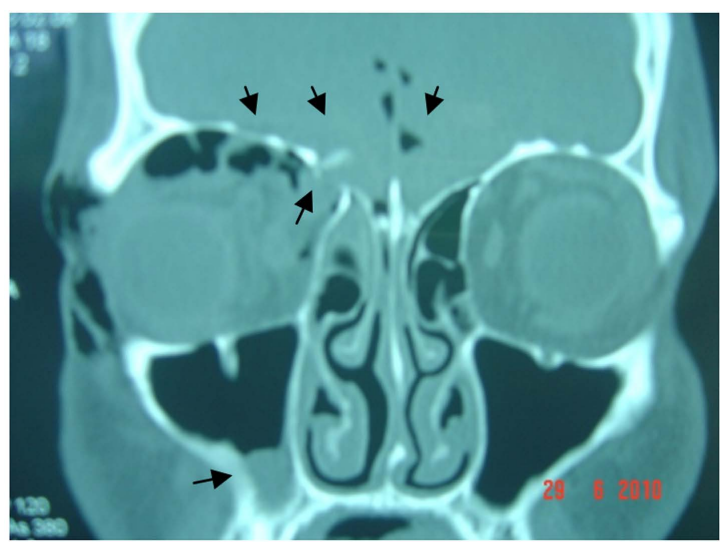

Figure 3. Orbital roof and temporal fossa emphysema and pneumocephalus, roof fracture.

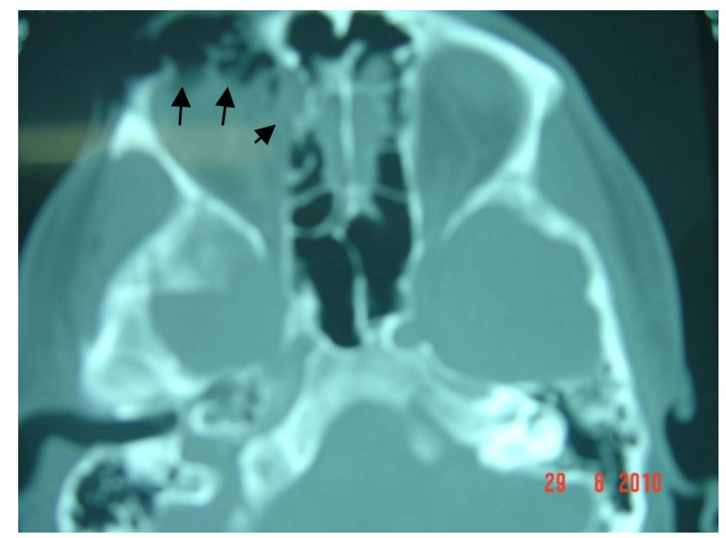

Figure 4. Ethmoidal/medial orbital fracture.

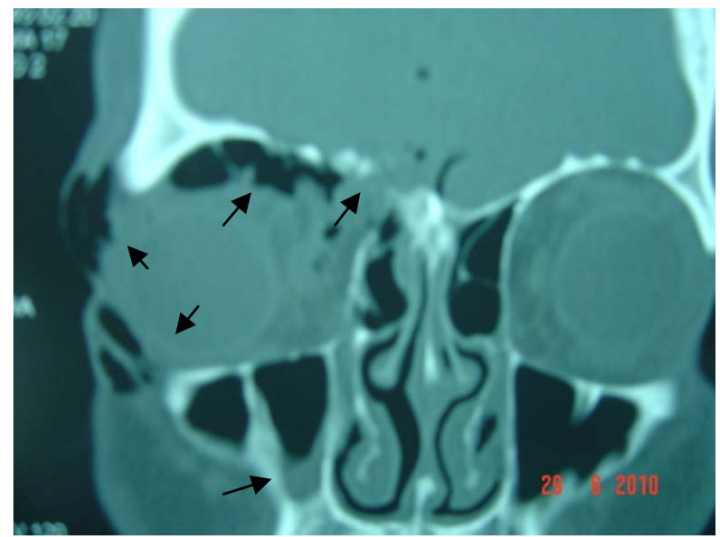

Figure 5. Orbital roof/medial wall corner, high possibility of naso-frontal duct injury, globe displacement inferolateral on right side.

disrupted, ct also showed what initially appeared as maxillary fluid level, but was later confirmed as pre-existing chronic sinusitis.

This injury was treated conservatively with antibiotics and NSAIDs for pain and inflammation; he was discharged after two days and kept under reviews for fear of developing any frontal sinus pathology iepneumocephalocele with no further complications two years onwards. 


\section{Discussion}

This is an unusual injury caused by unusual aetiology and circumstances. First, it is unusual for a blunt trauma on the eyeglobe and external orbital to cause a fracture in the orbital roof not the floor with the latter being the weakest out of both, therefore orbital floor fractures are the normal findings with blunt trauma not involving the rims with framework fractures [6]; second, the size of the fish, and the fact that the injury happens out of water are also not commonly encountered scenarios.

Two cases involving maxillofacial injury are reported in the literature ever involving this family of fish but by directly stabbing the orbit and brain [7] with the beaks, or orbit only in the second report [8]. To our knowledge, this is the first case of facial injury caused by the tail of this relatively small type of fish. The result is also an unexpected variant of orbital fracture in an area which is not normally regarded as common first line injury seen with the usual foreign blunt hit on eyeball/orbit producing the classical orbital floor, or floor/medial fracture. Alternatively, the fracture happens in one of the stronger points in the orbit which is the medial wall/roof corner without involving the external frame of the orbit.

\section{References}

[1] Wolff, K.D. (1998) Management of Animal Bite Injuries of the Face: Experience with 94 Patients. Journal of Oral and Maxillofacial Surgery, 56, 838-843. http://dx.doi.org/10.1016/S0278-2391(98)90009-X

[2] Ueeck, B.A., Dierks, E.J., Homer, L.D. and Potter, B. (2004) Patterns of Maxillofacial Injuries Related to Interaction with Horses. Journal of Oral and Maxillofacial Surgery, 62, 693-696. http://dx.doi.org/10.1016/j.joms.2003.12.010

[3] Fouda and Hermosa (1993) Checklist of Oman Fishes. Sultan Qaboos University Press, Sultanate of Oman.

[4] Staff of SCENR (2004) Convention on National Biological Diversity. Final NBSAP, University of Qatar Press, Qatar.

[5] Froese, R. and Pauly, D., Eds. (2006) Family Belonidae-Needlefishes. FishBase. http://www.fishbase.org/Summary/FamilySummary.cfm?ID=207

[6] Fonseca, R.J. and Walker, R.V.W. (1997) Oral and Maxillofacial Trauma. 2nd Edition, W. B. Saunders Co., St. Louis.

[7] McCabe, M.J., Hammon, W.M., Halstead, B.W. and Newton, T.H. (1978) A Fatal Brain Injury Caused by a Needlefish. Journal of Neuroradiology, 15, 137-139.

[8] Rahimian, O., Hage, R., Donnio, A. and Merie, H. (2012) Needlefish Jaw in Orbit. Journal Francais d'Ophtalmologie, 36, e41-e43. 